\title{
Nafarroa garaia: Basaburuko Harana: Arrarasko hizkera
}

\author{
LEIRE ZABALTZA AlEMAN
}

\section{SARRERA:}

Aurrean duzun lan hau, Nafarroako Basaburua haraneko Arraraskoa den Felisa Goizuetaren hizkeran dago oinarriturik; dena den zintan bai Felisak eta bai bere ahizpa Mariak hitzegiten dute; azken hau, Felisa baino zaharxeagoa da.

Felisa Goizueta 70 urteko emakume alarguna da eta orain dela 30 urte bizi da Iruñean. Aita Imotz haraneko Oskozkoa zuen eta ama berriz, Arrarats berekoa.

Esan behar da nik Felisa ezaguna dudala, auzokoa, hortaz horrek grabazioa giro franko lasaiean egiteko aukera eman dit.

Bestalde aipatu behar dut, gazteleraz hitzegiteko joera oso handia dutela hiru ahizpek; Iruñean bizi dira hiruak, eta hori grabazioan batzuetan nabaritzen da.

Beren hizkeraren transkipzioari buruz zenbait gauza aipatu nahi nituzke:

Felisak ahoskatu duen bezala transkribitu dut; batzuetan hitz ulergaitzak edo hitzen arteko hibridoak ahoskatu dituenez, bere horretan idatzi ditut.

Hortz postizoak dituela uste dut (ez nago ziur), beraz horrek fonetikoki ondorioak bazituela uste dut, batez ere hitz katean batzuetan txistukari afrikatuak agertzea eta beste batzuetan berriz, ez.

Bokalismoan, Basaburukoak diren zenbait ezaugarri direla eta, batez ere $u>0$ eta $i>e$, batzuetan ez nituen ongi antzematen, eta bi aldakiak idatzi ditut.

$<j>$ grafema erabili dut [ $x$ ] ebakera adierazteko, eta $<y>$ grafema berriz [j] ebakera adierazteko. Puntu honetan aipatu behar dut, gero ikusiko den bezala, asko harritu nauela bai [x] eta bai [j] egitea, Arraraskoek [i] besterik ez zutela egiten uste bainuen. Behar bada nire eragina izan ote daiteken pentsatu dut, nik $[x]$ ahoskatzen baitut. 
Bukatzeko esan behar dut lan honen helburua, aukeratutako hizkera honen eta transkripzioan agertzen diren arau eta ezaugarriak zehaztea dela.

\section{TRANSKRIPZIOA}

(...) Laarteko bordan. Baserrii zen tan bizi giñen ta gio, gio pues ne etor nizen onia pues ama...oitamar urtetan, oitamar urtetan, gio (e)ondu nitzen en la avenida Zaragoza eondu nizin beatzi urtez neskame, ta gio andek beatzi urten, gio ezkondu nizin, iru urten burun gizona il zitzion azidentin ta neskatoak zittun emezortzi illaate ta gio pues ayuntamentun tor zizien zea e, nola esaten da oiri...nola esa...enaiz akordatzen oain....or bizi da...e...tanatorioan ondoan bizi (d)ata tor zien ore zeara plazak pazela ( $\mathrm{g}$ )oan esan tzien ta illaateaten barneko yoan bear nun lania...ta zea iraazten zuten ordun,... guardii zen, guardi munizipala ta ordun ze iraatten zuten, zazpi mille pezta o eztai ze iraazten zuten, ta geo geldittu zitzien... mil seiszientas geldittu zitzien, oikin ze itten nun, diusez ta geo plazak pazirela ayuntamentun ta zeatzeko, presentatzeko esan tzien zeak ona etor zenak...(bein?) ta presentatu nitzin ta gio pues ala... illaaten burneko lanian asi nitzen tan oitabi urtesiz eondu nitzen ayuntamentun.

-Ta noiz jubilatu ziñen ba?

-Jubilatu nitzen...itten ttu sei urte.

$-A$, ainteste battu?

-Bai, bai, junioan.

-Nik uste nun guain dela bi urte o...

$-E z$, ez, ez. Sei urte betetzen ttut junioa (n)... ia ... bai, bai ta pues ze inbiazu $b a$, ta ordue allatuiskios sesentaizinko añotan... o iruetan oitabost urtetan jubilatu biaziñun ta jubilatu ta tasta, biño.... aspertu ....geinean.....zuk takizu ze lanak izaten tziin

-Ze lan izaten ziñuzten?

$-O \ldots$ garbittu, etxi...ta urte guzitan igual obran aitzen ziin ta zuk takizu nola paatzen zittuten dena ... txu... eskobatzen ( $\zeta$ ) zuten ta antxe garbitzelin, ta antxe aittu giñen oitabi urtes,(g)aixua, o sea ke, ez tao emen emen lan in bearra dao ta eztau... ta asi giñen... eskolan txantrealako, ta yoan bear giñun... seietako....txantrea, ta etzen ez billabeseik ta emendik yoaten giñen oñes zeara...plaza de toroan ondoan... andilek asten zela billabesa ta, esaten tziun billabesak, esaten tziulon noa...ra zozte orduotan, orduotan noa zazte, etziun artu artu naeli izaten, pentsatzen zun...estab...emakumiok non daeltze emen ta esaten giñun eskolaa joan beaginula... garbitzia ta ... bueno bueno sartu, sartu, ta yoaten giñen ta an...ats...zortzik arte, eskola sartzen tzen umi aik zortzita $(n)$ 
eta aitu giñen...goizeko...la(n) in biagiñun..ta ta be(i)s atsaldaien yoan bear giñun ta, oi....madre de dios...

-Jesus, a ze lana.

-Oix/se zen, lana? ez aon bezala, ikasti(a)uzte...zuk ikasten bauzte, bauzte, non sartzeko lekuu, biño guk zer giñakin ordun... diusez, ez giñakin ezta...an zeaitzen gu bete lanin, kanpuan, bete lanin, bete lanin, baten zeak garbitzen...oan...zeatu, bestian garbittulo bestin an eskardato/u zeak, patatak eta dena oitati( $k)$

-Bai oi esan bianizun, Arratsen ta bordan bizi ziñeten ez?

-Bordan, bordan

-Ta an ze lan itten ziñozten, bordan ze lan itten zen, sorotan o alorretan o?

-Sorotan ta alorretan ta dena oitan.

-Txerrik eta...aziendik eta baziñoten?

-Txerrik eta...ardik ez, beyek giñuzen ta txerrik eta beyek ta gue amak sei ume bazittun eta...sei ume eta bat il tzuten gerra( $n$ ) biarrena, ta bestii yoan tzen soldadu, gaztena, oitabi urtetan yoan zen (zere?)...lenau libratu zuten, ta gio gerra akaatu zenin... esan tziotela denbua kanbietu zela eta joan bearko zula zeara, soldadu kunplitzia ta oantxe eaman zuten oitabi urteta( $n$ ) ta besti zaarrena bes, eondu zen, eondu zen gerran, iru urte beni( $k$ ) in zittun( $n)$, gio gerra akaatu zen(in) Afrika eaman zuten ta Afriketik etorri zen geo yoan zen lanea... yoaten zen mendire, ta an izandu zun akzidenti.....(eztai ze izan zun)...il tzen, iru anaiek illek.

-Ta zenbat geldittu ziñeten ordun? ordun iru aizpe geldittu ziñeten?

-Iru aizpek, iru anaiek il tzen, ta iru aizpek b/pizi ga.

-Zu ta, gio sorotan ta zuk lanian aitzen ziñeten?

-Bai bai, antxe aitzen giñen, ta tia giñun guk aman aizpe, arek itten zittun gizonak bezalaxe lanak itten zittun, kanpon beyeke/in ta gurdikin ta alorretan ta dena, arren bearrak gue amak izandu zittun, gañeakuan ia ze inbiagiñun...geo nelik urtia in me nun aitte il zelaik ta zarrenak il zenin... bai ordun... zarra zen... oi...zarrenak zarrenak amar urte, in men zittun atte il zelaik... ta sei ume bagiñen, sei anai... ta tia gaxolua, majiña lan in ziun ta otxentaiseis años il zen, ia... lauetan oitasei urtetan il zen.

-Ta ordurarte lanian aitzen zen?

-Lanin, lanin, lanin, bete/i lanin... arrek e iruetan urtetan ta g(e)iotan, gizonak bezalaxe kanpua(n) igual ta esa ... esaten giño/un jainkuak arrei laoluntzen ziok eta itten zio... bete osasuna izandu zun... beno osasuna beti izan zun reumak eta atakatzen zioten, beliño beti bin̈ipin lanin, eskerrak arrei gañeakoan gu(e) amak ze in biazun sei umekilen....ia

-Zu Felisa ta eskolara ola juaten ziñeten, an Arratsen berian? 
-Bai, bai eskola ta joaten giñen... an eskolak oan ez te bezala astero... lau urtetan de, ...zazpi urtetan, ta zazpi urtetan ze in bear... urtes yoan giñen, amabi urte ta bete beyei kasuitzeko, kanpora ateatzeko, kanpoan e, beyei kasuitteko..ta ka...zea giñuzen ba, berdurek, kanpuak ola ta geo alorrak ondua(n) ta maizek eta ja... jatea ez joatiatik(k) ( $(j)$ an eoten giñen kaso itten. ta ze ustiuzu zenbat denboan yoan giñela eskola? zazpi urtetan asi ta beste lau urte in bagiñuzen? eskola! eztau, ta hamalau urtetan ia ez ziñun yoan bearrik, ta lanin, lanin, an... bete lanin, ta kanpua, errelire zenbat...joaten giñen z(e)atz(i)a, eskardatzia... enaiz akordatzen.... eskardatzia maizek eta, askotan errire juaten giñen, etxekoaken ta...

-Ta artayorran ta aitzen ziñeten?

-Bai, bai, yorran ailetzen giñen, bai, bai

-Ta artazuriketan ta?

-Denetan, denetan, denetan.

\section{TRANSKRIPZIOAREN IRUZKINA}

\section{FONETIKA}

\subsection{BOKALAK}

Honako hizkera honen bokalak, euskerazko sistema bokalikoan ohi denez, nahiko egonkortasunez mantentzen dira.

- / i / fonemaren aldaera fonetikoei buruz esan beharra dugu ageriko dela, gure transkripzioak agerian uzten duen bezala, [i] irekia. Hau, Basaburuko zenbait herritan gertatzen da, horien artean gure kasukoa den Arraratsen.

Hona hemen zenbait adibide:

-Herskarien ondoren:

handik

dabiltza

behiekin

beti

biño(<baina)

-Dardarkarien ondoan:

herrira

-Sudurkarien ondoan.

ni err[e]re

and $[e] k$

da[e]ltze

beyek $[\mathrm{e}] \mathrm{n}$

bet[e]
$b[\mathrm{e}]$ ño

bet[e]
$b[e]$ ño

$\mathrm{n}[\mathrm{e}]$

-Hitz hasieran, kontsonante herskari belarearen ezkerrean.Hona hemen adibide hauek (traskribiturik dagoena baino aurrerago agertzen da): 
ikusten

ikaarri(ikaragarri)
$>$ [e]kusten

$>$ [e]kaarri

Dena den aldaera hau ez da oso garbi nabaritzen ahal eta horregatik transkribitu ditut zenbait hitz bi grafemak jarriz. Bestalde zenbait kasutan hau ez da bete:

hemendik, Afriketik, hoitati(k), beni(k) (behinik behin).

Orreaga Ibarrak ${ }^{1}$ beste ingurune bat ere aipatzen du, alegia, txistukarien ondoko $/ \mathrm{i} / \mathrm{-z}$ bukaturiko aditz partizipio askotan.

Horrela ba hemen i>e gertatzen da.

- fe/ fonema hertsi egiten da [j] bokalerdi bihurtzeraino a-ren aurrean, honoko adibide hauetan:

$\begin{array}{lll}\text { one(r)a } & >\text { onea } & >\text { on }[\mathrm{j}] \mathrm{a} \\ \text { lane(r)a } & >\text { lanea } & >\mathrm{a}[\mathrm{j}] \mathrm{a} \\ \text { emakume auek } & >\text { emakum[j]auek } & >\text { emakum[j]ok } \\ \text { bestean } & >\text { best[j]an } & \\ \text { kunplitze(r)a } & >\text { kunplitz[j]a } & \\ \text { urtea } & >\text { urt }[\mathrm{j}] \mathrm{a} & \\ \text { bear ziñun } & >\text { b[j]aziñun } & \\ \text { bear zun } & >\text { b[j]azun } & \\ \text { joatea(ga)tik } & >\text { joat[j]atik } & \\ \text { eskardatze(r)a } & >\text { eskardatz[j]a } & \end{array}$

Dena den, zenbait kasutan ez dut hertsidura hau antzeman eta /e/fonema bere horretan gelditu dela iduritu zait: zeak; in bear; ateatzeko; bearra

Beraz e+V > j V gertatzen da.

Orreaga Ibarrak joera honekin batera parekatzen duen e(i/-txistukaria, ez du iduri betetzen denik etxe adibidean behinik behin: etxi; etxekoaken. (Hala ere traskribiturikoa baino aurrerago bada adibide bat, itxin) ezkero:

/e/ fonemak bere tinbrea aldatu egiten du hurrengo silaban $/ \mathrm{u} /$ bat izan

$\mathrm{e} \rightarrow \mathrm{i} / \mathrm{-u}$

behar zenuen
genuen
genuela
ginuzen

$$
\begin{aligned}
& >\text { [bjazinun }] \\
& >\text { [ginun] } \\
& >\text { [ginula }] \\
& >\text { [ginusen }]
\end{aligned}
$$

Ibarrak dioenez 1 , kontsonante sudurkarien desagertzearen ondorioz, /e/ bokala /a /ren atzetik aurkitzen denean /ae/ eta /oe/taldeak osatuz, ixtera jotzen du

I Orreaga InaRRA MuRILlo Ultzamako hizkera. Inguruko euskalkiekiko harremanak. Nafarroako Gobemua 1995, 86. orrialdea. 
eta [ai], [oi] diptongoak bihurtzeko joera erakusten du. Era berean, sudurkaria galtzen da silabaren bukaeran, posizio inplosiboan beste sudurkari bat dagoenean.

Gure kasuan ez da [ai] gertatzen, edo nik ez dut horrela sumatu, eta [ae] bere horretan gelditu dela iduritu zait. Horrelako adibideak aurkitu ditut (transkribiturik dagoena baino aurrerago):

$\begin{array}{ll}\text { izanen } & >\text { [isaen] } \\ \text { emanen } & >\text { [emaen] }\end{array}$

$-1 a /$ fonemari dagokionez, a mugatzailearen eransketaren ondorioz sorturiko aldaketa ezberdinak ikusten ahal ditugu:

Asimilazioa:

-it -a > -ii: baserrii, guardii, bestii

Asimilazioa eta bokal desagerketa:

$-\mathrm{i}+$-a > -i: etxi

-e+ -a > - i: azidentin, lanin, zenin, akzidenti, bestin (baina aurreraxeago «bestian»).

Pluraleko kasua sail honen barnean sartzen ahal dela uste dut:

-i + -ak > -ik: txerrik, ardik, zortzik, begik.

- a organikoaren asimilazioa: a(e/i, u-: mila $>$ mille

a mugatzailearen ixtea: a(e/i, u-

ordua $>$ ordue

behiak > beyek

hilak $>$ illek

ahizpak > aizpek

berdurak $>$ berdurek

maizak > maizek

$\rightarrow$ ra adlatibo kasuko lal ren ixtea:

mendira > mendire

lail diptongoa+ a mugatzailea: ixtea:

bei + ak $>$ beiek

anai $+\mathrm{ek}>$ anaiek

/e/ batez hasitako hitz batzuetan lehen silabako kontsonante frikari albeolarea galdu eta e $(*$ i $>\mathrm{j})>\mathrm{j}$ biladabidea betetzen dela aipatzen da Basaburua eta Imotzerako; baina hemen ez du iduri hau betetzen denik; horrela, hau dugu: 
- /o / fonemari buruz Ibarrak dio (93. orrialdea) askotan - a morfema mugatzailearen ondoan, $/ \mathrm{w} /$ izatera iristen dela. Era berean hitz erdian ere o+a taldean $\rightarrow$ oa hertsia ebakitzen dela.Transkribitu dudanaren arabera, badirudi /o/ fonema nahiko bere horretan ahoskatzen duela: neskatoak, yoaten, etxekoaken, ondoan, gañeakoan.

Batzuetan ordea /u/: kanpuan, onduan.

- $-/ \mathrm{u}$ / fonemari dagokionez esan daiteke $u>$ o bilakabidea ikusten ahal dugula, nahiz eta traskribitzerako garaian bi grafemak jarri: garbitto, eskardato, giñon, laontzen, eztakizo.

Batzuetan ordea [u] garbi bat aditu dut: garbittu.

Bestalde aipatu beharra da -a mugatzailearen eransketaren ondorioz sortzen den asimilazioa: $-\mathrm{u}+-\mathrm{a}>-\mathrm{uu}$ : lekuu, pisuu (transkribiturik dagoena baino aurrerago).

- Beheranzko diptongoei dagokienez, zera aipa dezakegu:

-eu > iu egiten du: deusez $>$ diusez

(besteren batean ordea deusez gelditu da)

-ai: -berdin mantentzen da batzuetan: enaiz. Beste batzuetan monoptongaketa gertatzen da: ai >a: enaz (traskribiturikoa baino aurrerago), zattut.

ei: - batzuetan ei>e, monoptongaketa egiten du: beinik $>$ benik

-ei > i monoptongaketa egiten du: (behinik behin) beinik bein $>$ binipin

Honetaz gain, diptongo bigarrenkari franko aurki ditzakegu: oitamar; oiri; oikin; eztau; aik; aittu; beis(<berriz). Hau hitz batzuetan monoptongaturik azaltzen da: bes.

- Goranzko diptongoei buruz esan dezakegu, arestian aipatu ditugun [ea] eta [oa] taldeak [ja] eta [wa] ebakitzearen ondorio direla.

- Hiatoak, bokalen sailean aipatu ditugu. Hala ere ager dezagun hemen hiato batzuren murrizketaren adibidea:

$$
\begin{array}{r}
-\mathrm{i}+-\mathrm{e}>-\mathrm{j}-: \text { guzjetan }>\text { guzitan } \\
-\mathrm{u}+-\mathrm{e}>-\mathrm{u}-: \text { nuen }>\text { nun } \\
\text { zuela }>\text { zula }
\end{array}
$$

- Sinkopa: Ez du ematen etekin handikoa denik. Bizpahiru adibide baditugu (Transkribiturikoa baino aurrerago): txerkomik; pastu; barneko; ikasteuzte; bauzte. 
- Aferesirik ez da gertatzen. Kasu zehatzen batean, baina badirudi hizketa azkarraren ondorioa dela.

- Partizipioetako -i, sinkopatu egiten da: etor zenak; etor zien; etor giñen (aurrerago) eta era berean geroaldian ere hau ikusten dugu: etorko giñen (transkribiturikoa baino aurrerago).

\subsection{KONTSONANTEAK}

Kontsonante herskariei dagokionez, argi ikusten da bilakabide baten indarra, izan ere $/ \mathrm{b}, \mathrm{d}, \mathrm{g} /$ segmentuak galtzeko joera nabarmena baita ; eta $/ \mathrm{r} / \mathrm{ere}$ bai:

$$
g \rightarrow \emptyset / v-v
$$

hogeitamar > oitamar

egondu $>$ eondu

egiten $>$ itten

zigun $>$ ziun

gehiagotan $>$ g(e)iotan

laguntzen $>$ laontzen

lehenago $>$ lenau

bigarrena > biarrena

$d \rightarrow \infty / v-v$

uste duzu > ustiuzu

dago $>$ dao

ikasten duzute $>$ ikastiuzte

baduzute $>$ bauzte

bizi da eta > bizi a ta

$b \rightarrow \emptyset / v-v$

hilabete > illaate

hilabete baten $>$ ilaateaten

irabazten $>$ iraazten

dabiltza > deltze

akabatu $>$ akaatu

ahizpa ba $\mathrm{t}>$ aizpeat (aurrerago) 
- $r \rightarrow \emptyset / v-v$

orain $>$ oaen, oan

gero $>$ geo

allatu ezkeroz $>$ allatuiskios

aritzen $>$ aitzen

paratzen $>$ paatzen

billabesarik $>$ billabeseik ${ }^{2}$

nora $>$ noa

eskolara > eskolaa

lanera > lanea (baina, mendira > mendire, ez da galtzen)

gure $>g u(e)$

zelarik > zelaik

Dardarkari bikoitzaren galera:

berriz $>$ be(i)s

arratsaldean $>$ atsaldan

$|-r|>\emptyset$ azkeneko posizioan:

-zer galdetzailean: ze iraazten zuten; ze itten nun ; an ze aitzen; ze ustiuzu -behar aditzaren ondoan:

$$
\begin{array}{ll}
\text { zer egin behar duzu } & >z e \text { in beazu } \\
\text { jubilatu behar zenuen } & >\text { jubilatu biaziñun } \\
\text { zer egin behar zuen } & >\text { ze in biazun }
\end{array}
$$

- - rtz/ -st kontsonanteez osatutako taldeei buruz, esan behar da Arraratsen (eta orohar Basaburuan) - st multzoa dugula: oitabost, bestian. bestin...

Honekin loturik, Arraratsen esan esaten da eta ez, erran.

- Hitz hasierako *j-ren ebakeran [j] ebakera eta aldi berean eta zenbait kasutan $[\mathrm{x}]$ ebakera ere antzematen dugu.Hona hemen adibideak:

[j] ebakera

yoan bear giñun

emendik yoaten giñen

ta bes atsaldan yoan bear giñun

ta bestii yoan tzen soldadu

geo yoan zen lanea

urtes yoan giñen

yorran aitzen giñen

yendiek (aurrerago)

yostatzea (《»)

${ }^{2}$ Iruñean horrela esaten zaje hirian barna ibiltzen diren autobusei. 
Beste fenomeno bat ere hemen aipa dezakegu, nahiz eta behar bada aditz morfologian ere sartzen ahal den: aditz laguntzailearen bigarren pertsona singularrak elementu protetiko bat hartzen du: $y-$

Gure kasuan adibide bakarra dugu baina hau berresten ahal duela iduritzen zait: (traskribiturikoa baino aurrerago)

yoan tzen ta esaten giñon, ez txaila atia, gio etortzen yaizenin bes igual kastigatuko yau.

- f- > p- bilakabidea betetzen dela iduri du, baina ez dugu adibide bat besterik:

$$
\text { festa > pesta (aurrerago) }
$$

Dena den famille, farmazi, fuerte esaten du aurrerago.

- Bustidura: franko emankorra dela iduri du. Bustidura gertatzen da honoko ingurune hauetan:

- Bustidura automatikoa: bai hitz barnean, bai morfema mugetan ere.

- $\mathrm{t} / \mathrm{i}-\mathrm{v}$ :

zittun, geldittu, itten, ttu, ttut, garbittu, zittuten, aittu, bazittun, kasuitteko.

(Pluragilearen bustidurari dagokionez, aditzeko aniztasuna adierazteko - tt dugu adizkiaren hasieran. Ez dago bustidurarik gabeko formarik)

- $\mathrm{t} \mathrm{j}-\mathrm{v}:$ atte.

Esan behar da bustidura automatikoa - i ren ondoren hortzetako heskari ahoskabea palatalizatzen duena, ez dela ingurune guztietan gertatzen. Ondorengo morfema hauekin ez da bustidurarik sortzen:

- tan inesiboaren morfema: zortzitan, oitan.

- tik,-tiken ilatiboarenak: oitatik, Afriketik.

(Ibarrak atal honen barnean - ta /-te partizipioarena eta - te aditzen 3 . pertsonaren morfema eta azkenik - ten aditz burutugabeen morfema aipatzen ditu)

-1/i-v: illaate,mille, illek, ollaskoak (aurrerago), isil-isille(aurrerago).

-n/ i- v: biaziñun, giñen, giñun, giñula, giñakin, giñuzen, majiña, ziñun.

-n/j-v: biño, biñipin, gañeakoan.

\section{MORFOLOGIA}

\subsection{IZEN MORFOLOGLA}

- Instrumentaleko - $s$ aldaera:

Gure hiztunak instrumentalean -s egiten du ia beti, hala ere instrumentalerako $s / z$ ren nolabaiteko lehia dagoela iduri du: 
$-\mathrm{s}$

oitabi urtes

yoaten giñen oñes

urtes yoan giñen

kantus ez (aurrerago)

oñes etor biaziñun $(\alpha)$

zenbat aldis yoaten giñen( $($ )

mendis ( ()
$-Z$

beatzi urtez

zazpi o zortzi illatez

(aurrerago)

eztait zenbat kilometroz

(aurrerago)

Instrumentala $-\mathrm{s} \mathrm{z}$ egitearen eragina izan daiteke honako hau:

berriz > bes

allatu ezkeroz $>$ allatuiskios

Hirugarren graduko erakusleak /r/z egiten ditu gehienetan: arren bearrak; arrek; arrei.

Baina, arek itten zittun

Hona hemen gure hiztunak erabilitako beste erakusle batzuk(batzuk traskribiturik dagoena baino arrerago daude):

-Singularrean:

Absolutua: au, oi, oreluel wa

Ergatiboa: orrek

-Pluralean:

Absolutua: $o k$, oik, aik

Ergatiboa: ok, oik, aik

Genitiboa: aien

Soziatiboa: oikin, aekinlaikin/ aiekin

Inesiboa: otan, oitan

Ablatiboa: oitatik/ oietatik

Izenordain pertsonalei buruz esan behar da batez ere $i>$ e eta $u>0$ aldaketa fonetikoak direla eta «ne»; «nek» eta horrelakoak egiten dituela. Bigarren pertsona plurala «zuk» da eta ez «zuek»: zuk ikasten bauzte.

Hona hemen Ibarrak agertzen duen koadroa: Honako hauek dira Basaburuan erabiltzen direnak. Aldaketa fonetikoak direla eta, nahiko ezberdinak suertatzen dira forma hauek, eta horregatik, beste koadro batean sartu ditu:

\begin{tabular}{|l|l|l|l|l|l|}
\hline 1. & ne & hi & gu & zo & zuk \\
\hline 2. & nek & hik & guk & zok & zuk \\
\hline 3. & nei & hire & guei & zoi & zure \\
\hline 4. & nee & hirii & goe,guu & zoo & zuun \\
\hline 5. & nerii/nei & hirii & gurii & zurii & zuuna \\
\hline 6. & neentzat & hiitzat & guretzat & zoontzat & zuuntzat \\
\hline 7. & neeken & hiiken & guken & zooken & zuken \\
\hline
\end{tabular}




\begin{tabular}{|l|l|l|l|l|l|}
\hline 14. & netaz & hitas & gutas & zootas & zuutas \\
\hline 15. & neegan & hiigan & gugan & zoogan & zuugan \\
\hline 16. & neegana & hiigana & gugana & zoogana & zuugana \\
\hline 17. & neegañieaño & hiigañeaño & guugañeaño & zoogañea-ño & zuugañaiño \\
\hline 18. & neegandik & hiigandik & gugandik & zoogandek & zuungan-dek \\
\hline 19. & neegatik & híigatek & gugatek & zoogatek & zungatek \\
\hline
\end{tabular}

- -Zenbatzaileei dagokienez, hona hemen gure transkripzioan ateratakoak:

Zenbatzaile zehaztuak ordinalak

3-iru biarrena

6-sei

7-zazpi

8-zortzi

9-beatzi

10-amar

14-hamalau

18-emezortzi

22-oitabi

25-oitabost

30-oitamar

60-iruetan hogei

65-iruetan oitabost

86-lauetan oitasei

Azpimarratzekoa iruditzen zait -tan hogei egitura hauekin eraikitako zenbatzaile hauek nabarmentzea, izan ere honatx zer esaten duen Orreaga Ibarrak (331. orr.):

«(...) hogei-rekin osatutako zenbatzaile batzuk $(60,80)$-etan hogei egituraz eraikiak dira: lauetan hogei, iruetan hogei, Ultzaman, Atez eta Anueko herrietan. Imotzen eta Basaburuan, ordea, txandaketa nabarmentzen hasten da (ik. Echaide 1989:285,286 galderak) eta berauetan argi ikusten da iruroei eta larogei formak Basaburukoak direla».

- Ergatibo singularra eta pluralaren arteko sinkretismoa gertatzen da hemen. Nahiz eta adibide askorik ez izan, hona hemen traskribiturikoa baino aurrerago dioena:

Mezaalekoak (Mendizabalea) ola etxe aundi...oik zuten diru geixau, tienda re bazuten, biño beste aiñekoak keba.

Ablatibo pluralean badirudi - etatik dagoela eta ez -etarik: oitatik. 


\subsection{ADITZ MORFOLOGIA}

-Trinkoek iraganaldian badirudi -a - erroa dutela: zer giñakin; ez giñakin; asko zakin; etzakin arrek...

-Partizipioetan -rik eta -a darabilzki:iru anaiek illek; itxin,desespeatuik

-Aditzondoa badirudi absolutu singularrean darabilela: geldittu zen isil-isithe (transkribiturikoa baino aurrerago) antxe yoaten tzen bakar-bakarra ( $(«)$

Geroago ordea mugagabean erabiltzen du beste bat: gabeako etortzen tzen mantso-mantso(aurrerago)

-Partizipio analogikoa egiten ditu: eondu nizin; eondu zen; izandu zittun. (baina beste behin beti izan zun esaten du)

-Aditzean denborazko marka - nean/-larik erabiltzen ditu: atte il zelaik ta zarrenak il zenin... joaten giñelaik ta atsaldin bezpeta joaten giñenin.

-Geroaldia aditzetan -en egiten du, kontsonantez bukaturikoak: aman izaen nittun; izaen nun; emaen niken.

-Eta bukatzeko, ezaugarri orokor batzuk aipatuko ditut: zakite.

Iragankorretako hirugarren pertsona pluralean - te egiten dute: dute, zute,

Iragankorretako bigarren pertsona plurala - te: duzte, dakizte, ziñuten.

(hurrengo orriek Arrarasko aditz laguntzaileak zeintzuk diren dakarte)

\section{ONDORIOAK}

Nafarrera garaiko bereizgarriak baditu:

Sinkoparen aztarnak ageri dira.

Instrumentalean $-s$ egiten du.

Kontsonantez bukaturiko aditzetan geroaldia -en egiten du.

Gaztelaniazko $\rightarrow$ on bere horretan gorde da.(Iruzkinean ez dugu esan baina aurrerago fronton bat eta kordiona esaten du)

Aditzetako bigarren pertsona singularra $y$ - da.

Mendebala, Gipuzkoa eta Nafarroa garaiko sartaldea hartzen duten isoglosak:

-st- kontsonante multzoa dago.

Ablatibo pluralean -etatik dago.

Trinkoek iraganaldian - $a$ - erroa dute. 
Partizipioetan - rik eta $-a$

Aditzondoa mugagabean eta absoluto singularrean egiten du.

Nafarroa garaian sortalderago iristen diren isoglosak

Ergatibo singular eta pluralaren arteko sinkretismoa.

Erdialdeko hizkerak egindako berrikuntzak:

Iragankorretako hingarren pertsona plurala -te da.

Iragankorretako bigarren pertsona plurala - $t e$ da.

Asimilazio- bustidura franko indartsua da.

Partizipio analogikoak.

$f \rightarrow p$ - bilakaera

Edun aditzean - $\mathbf{u}-$ da erroa nahiz $\boldsymbol{u}>\boldsymbol{o}$ gertatu.

Hirugarren graduko erakusleetako arre, arri, arrekin egiten du.

Nafarroa garaiko sartaldean maiz betetzen den $\boldsymbol{u}>\boldsymbol{o}$ bilakaera betetzen da.

Eremu murritzagokoa den $i>$ e bilakaera betetzen da.

Partizipioetako - $i$ bokalaren sinkopa eta geroaldietan ere bai.

\section{BIBLIOGRAFIA:}

IBARRA MURILlo, Orreaga (1995): Ultzamako hizkera. Inguruko euskalkiekiko harremanak. Nafarroako Gobemua Iruñea.

YRIZAR DE, Pedro (1992): Morfología del verbo auxiliar alto navarro septentrional (estudio dialectologico), tomo 1, Nafarroako Gobernua, Euskaltzaindia, Iruñea.

YRIZAR, Pedro (1981): «Los dialectos y variedades del vascuence», Contribución a la dialectología de la lengua vasca (I). Donostia, Caja de Ahorros Provincial de Guipúzcoa.

URQUIzU, Patricio (1996): Gramática de la Lengua Vasca, Cuadernos de la UNED, Universidad Nacional de Educación a Distancia, Madrid. 